\title{
SEGURANÇA DO PROFISSIONAL DE SAÚDE: O QUE MUDOU FACE À PANDEMIA?
}

\author{
Tanise Pereira Santini'; Flavia Saleh²; Luiza Fortes Lamberty3; Cristina de \\ Freitas Rodrigues ${ }^{4}$; Karen Ariane Bar ${ }^{5}$; Dirce Stein Backes ${ }^{6}$.
}

\begin{abstract}
RESUMO
Objetivo: Promover a segurança do profissional de saúde por intermédio da Incubadora de Aprendizagem. Metodologia: Trata-se de uma pesquisa-ação realizada a partir da identificação de demanda no contexto institucional - necessidade emergente de garantir a segurança do paciente e do profissional de saúde face à pandemia provocada pela COVID-19. O estudo foi realizado entre agosto/2020 e maio/2021, com a participação dos profissionais de saúde de um hospital de ensino da região central do Rio Grande do Sul. Resultados: Da análise dos dados emergiram duas categorias temáticas: Segurança do trabalhador: movimento indutor de reflexão; Da postergação à reconquista de cuidados básicos. Considerações finais: Os resultados do estudo denotam, que promover a segurança do profissional de saúde, pressupõem desenvolver, a priori, mecanismos de (re)significação e sensibilização voltados à tarefas cotidianas, em meio à pandemia provocada pela Covid-19.
\end{abstract}

Palavras-chave: Enfermagem; Covid-19; Segurança do Trabalhador.

Eixo Temático: Educação, Cultura e Comunicação.

\footnotetext{
${ }^{1}$ Estudante do Curso de Enfermagem da Universidade Franciscana (UFN). Bolsista voluntária Probic/FAPERGS. E-mail: tanisesantini@hotmail.com

${ }^{2}$ Estudante do Curso de Enfermagem da Universidade Franciscana (UFN). Bolsista

Probic/FAPERGS. E-mail: flaviasaleh222@gmail.com

${ }^{3}$ Estudante do Curso de Enfermagem da Universidade Franciscana (UFN). Bolsista voluntária Probic/FAPERGS. E-mail: luizaflamberty@gmail.com

${ }^{4}$ Mestranda em saúde materno-infantil pela Universidade Franciscana. Enfermeira do Centro de Controle de Infecção Hospitalar. E-mail: bkarenarianebar@gmail.com

${ }^{5}$ Mestre em saúde materno-infantil pela Universidade Franciscana. Enfermeira gerente de enfermagem. E-mail: enfermagem.hcs@sefas.org.br

${ }^{6}$ Doutora em enfermagem. Coordenadora do Mestrado em Saúde materno-infantil da Universidade Franciscana. E-mail: backesdirce@ufn.edu.br
} 


\section{INTRODUÇÃO}

O Sistema Único de Saúde (SUS) tem por dever constitucional zelar pela formação permanente dos profissionais de saúde, com ênfase no seu desenvolvimento técnico-científico e humano. A Política Nacional de Educação Permanente em Saúde (PNEPS) estabelece como diretriz a (re)significação das práticas profissionais, bem como a garantia de segurança do trabalhador enquanto sujeito da ação (BRASIL, 2009). Esse processo participativo é construído com base no diálogo, na reflexão sobre a prática diária e em ações individuais e coletivas de caráter prospectivo (ROSSETTI et al., 2019).

Ressalta-se a importância de promover processos educativos acerca da segurança do trabalhador, sobretudo, em períodos pandêmicos como o atual evento provocado pela COVID-19, nos quais os profissionais se encontram em vulnerabilidade física, emocional, social e espiritual (SOUZA; SOUZA, 2020). A pandemia da COVID-19 gerou medos, angústias e incertezas em na população em geral, mas atingiu em especial os profissionais de saúde, considerados os protagonistas no controle da propagação do vírus (LISA ROSENBAUM, 2020).

Os profissionais de saúde vivenciam, cotidianamente, o desgaste emocional pela sua atuação direta com fatores estressores no ambiente de trabalho que se exacerbam em momentos de epidemias e pandemias. A pandemia por Covid-19 é uma emergência de saúde pública e representa um dos maiores desafios da humanidade e da Ciência desde a Segunda Guerra Mundial e a sua interface com a segurança do paciente e do trabalhador tem fundamental importância, durante e após a crise pandêmica (DANTAS, 2021).

A pandemia por Covid-19 é uma emergência de saúde pública e representa um dos maiores desafios da humanidade e da Ciência desde a Segunda Guerra Mundial, a sua interface com a segurança do paciente e do trabalhador tem fundamental importância, durante e após a crise pandêmica (DANTAS, 2021).

A Incubadora de Aprendizagem se configura, nesse processo, como espaço de acolhida e de (re)significação de saberes e práticas que conduzem à Educação Permanente e à formação ao longo da vida, conforme já proposto em estudo previamente publicado (BACKES et al., 2015). Permanece como questionamento: 
Como promover a segurança do profissional de saúde pela mediação da Incubadora de Aprendizagem? Objetivou-se promover a segurança do profissional de saúde por intermédio da Incubadora de Aprendizagem

\section{METODOLOGIA}

Trata-se de uma pesquisa-ação realizada a partir da identificação de demanda no contexto institucional - necessidade emergente de garantir a segurança do profissional de saúde frente à pandemia provocação pela Covid-19. Assim, após a identificação da demanda e discussão prévia do cronograma com as gerências locais de um hospital de médio porte, no qual está instalada a Incubadora de Aprendizagem, realizou-se intervenções com foco na segurança do trabalhador de saúde.

As intervenções, exercidas por estudantes de iniciação científica e mestrandos, com o apoio de Enfermeiros gestores, foram realizadas com os profissionais de saúde de um hospital de ensino da região central do Rio Grande do Sul, entre os meses de agosto/2020 e maio/2021, a partir da sistematização de um cronograma de intervenções, mediado pela Incubadora de Aprendizagem. As atividades foram realizadas de forma criativa e interativa, de modo que cada um dos profissionais se sentisse participe e sujeito do processo. Dentre as demandas prioritárias foram consideradas: autoproteção; paramentação e desparamentação profissional; (re)significação da lavagem de mãos e do uso da máscara, considerados cuidados básicos no combate à pandemia.

Participaram do processo de intervenção cerca de 80 profissionais de saúde. Os encontros foram previamente agendados, dois por turno, com o gestor de cada unidade, no sentido de possibilitar o maior número de colaboradores. A duração média de cada encontro foi de 50 minutos e foram organizados de modo a contemplar os três turnos de trabalho. Os encontros foram realizados de forma presencial, respeitando as normas de distanciamento social e higiene, a partir de temáticas e leituras prévias, a fim de mobilizar e ampliar a participação. As temáticas dessa pesquisa também foram abordadas de modo online, por meio de plataformas de domínio dos participantes da pesquisa, a fim de possibilitar reflexões sobre o cotidiano de trabalho. 
Os dados de pesquisa foram coletados de modo online, após as intervenções, por meio de entrevistas agendadas com os profissionais de saúde. Os dados foram coletados a partir de questões norteadoras, quais sejam: Fale-nos sobre como percebeu as intervenções sobre a segurança do trabalhador? O que este processo despertou em você? O que mudou em sua forma de pensar e agir face a pandemia da Covid-19? O que você considera que pode ser diferente em seu trabalho, a fim de garantir a segurança do paciente e a sua como profissional?

Os dados de pesquisa, após transcritos e organizados, foram analisados com base na técnica de análise de conteúdo temática sistematizada em três etapas. A primeira etapa, denominada pré-análise, consiste em retomar as hipóteses e os objetivos iniciais a fim de orientar a interpretação final. A segunda etapa consiste na exploração do material, do qual foram analisados os textos sistematicamente de acordo com as categorias. A terceira etapa, compreende o tratamento dos resultados, inferência e a interpretação, do qual as categorias que serão utilizadas como unidades de análise serão submetidas a operações estatísticas (MINAYO; COSTA, 2018).

A pesquisa considerou as recomendações da Resoluções do Conselho Nacional de Saúde $n^{\circ}$ 466/2012 (BRASIL, 2012). Considerou-se, ainda, as recomendações do Ofício Circular n 2/2021 (BRASIL, 2021). O projeto de pesquisa foi aprovado pelo Comitê de Ética em Pesquisa, sob o número 4.253.905. Para manter o anonimato dos profissionais de saúde, as falas foram identificadas no texto com a letra "PS" de profissional de saúde, seguida por um algarismo arábico, correspondente à ordem das falas.

\section{RESULTADOS E DISCUSSÃO}

Da análise dos dados emergiram duas categorias temáticas: Segurança do trabalhador: movimento indutor de autorreflexão; A (re)significação de cuidados básicos em saúde.

\section{SEGURANÇA DO TRABALHADOR: MOVIMENTO INDUTOR DE AUTORREFLEXÃO}


A Incubadora de Aprendizagem enquanto tecnologia indutora e (re)significadora de saberes e práticas profissionais, mobiliza estratégias para que o profissional se identifique como cuidador e cuidado, considerando ser ele o mediador da segurança do paciente. Nesse sentido, a educação permanente é referida como impulsionadora de reflexão e autocrítica, conforme descrito por um dos profissionais:

"A educação permanente faz com que o integrante repense a forma que ele está agindo, como está conduzindo, rever as técnicas, o cuidado com paciente, ele sensibiliza o trabalhador, em busca da melhoria dos processos" (PS12).

Denotou-se, na fala dos participantes, a importância dos momentos de reflexão prévia realizados na Incubadora de Aprendizagem, os quais possibilitaram a troca de conhecimentos entre os trabalhadores e o fortalecimento dos vínculos de confiança e empatia. Sob esse enfoque, a educação permanente se traduziu em movimento que possibilita rever atitudes e condutas, além motivar os profissionais para a atuoavaliação e o aprendizado permanente.

"Esse processo despertou em mim o momento de refletir sobre o que tenho dificuldades e como saná-las através do conhecimento e das orientações a partir desses momentos pela incubadora"(PS10).

A Incubadora de Aprendizagem viabilizou momentos de compartilhamento de saberes entre os profissionais de saúde, proporcionando o despertar de novas ideias e um senso de autocrítica. Alguns colaboradores mencionaram o quanto a Incubadora Ihes possibilitou um novo pensar e agir, o qual contribuiu para a qualificação do processo de trabalho, mas sobretudo para a percepção de que o aprendizado se dá ao longo da vida.

"É importante os momentos de educação permanente, para as trocas de conhecimentos entre os colegas. O aprendizado deve ser contínuo e permanente, sempre se tem algo a aprender"(PS11).

A multiprofissionalidade foi evidenciada como um ponto favorável, pela ampliação de conhecimentos e a compreensão de cada parte no todo do processo de trabalho. Notou-se na fala de um colaborador, a relevância de espaços acolhedores e que despertam o sentimento de equipe e a necessidade de mudança continua e permanente. 
"Mais do que atualização tem nos permitido otimizar processos e mudanças em nossas atitudes enquanto profissionais, estendendo isso ao crescimento interpessoal (multi e interdisciplinar)"(PS17).

A Incubadora de Aprendizagem, mediada por metodologias significativas, viabiliza espaços de encontro consigo mesmo e com o outro. Para além dos conteúdos temáticos, os encontros, mesmo que na forma online, despertaram sensibilidade, reconhecimento, empatia e fortaleceram o pacto coletivo pelo cuidado e a segurança uns dos outros.

\section{A (RE)SIGNIFICAÇÃO DE CUIDADOS BÁSICOS EM SAÚDE}

A pandemia da COVID-19 foi impulsionadora, na compreensão dos profissionais, no que se refere à retomada de cuidados básicos que antes haviam sido banalizados e/ou relegados a um segundo plano. Percebeu-se na fala dos profissionais, no entanto, que não basta retomar a relevância dos cuidados básicos, mas que também é necessário desenvolver mecanismos de sensibilização e empatia, a fim de assegurar o uso correto dos equipamentos de proteção individual (EPIs), como por exemplo a utilização da máscara.

"Difícil definir mudança num momento tão atípico e adverso em que vivemos no qual está sendo necessário a reinvenção continua frente ao que diariamente está sendo descoberto, mas algo que deveríamos tratar com ênfase está sendo ainda mais necessário: empatia”(PS3).

Evidenciou-se, em várias falas de participantes, que a pandemia de COVID-19 reiterou à necessidade de promover a autoconsciência em relação aos cuidados básicos. Desse modo, a realização da higiene das mãos, os cuidados com os EPIs e o uso correto do álcool em gel foram alguns dos elementos abordados na educação permanente. Denota-se, no entanto, que alguns colaboradores agem motivados pela "cobrança" por parte de chefias, o que não necessariamente repercutirá em melhores práticas profissionais.

“...A pandemia proporcionou o resgate princípios básicos, e de nós trabalharmos o cuidado..."(PS19), 
"A pandemia trouxe à luz cuidados de enfermagem básicos, seja com EPIs, cuidado com pacientes, trazer à tona essas discussões e discutir em questão da cobrança, o por quê realizar a colocação do EPI adequada, de que forma coloca a máscara..." (PS20).

Outro aspecto recorrente está relacionado à sensibilização e ao estímulo dos profissionais de saúde no que se refere à construção de ambientes/espaços propulsores de mudanças individuais e coletivas. Denotou-se, na fala de participantes, que para alguns colaboradores a educação permanente se reduz a "perda de tempo", impressão que Ihes incomodava, visto que estes profissionais há haviam compreendido o real significado da aprendizagem ao longo da vida.

"É preciso sensibilizar os trabalhadores que não é uma perda de tempo... é um espaço de reflexão, de pensar que você pode melhorar a tua prática, novas possibilidades e novas ações de proteção e promoção à saúde. Agregar novas coisas ao nosso ambiente de trabalho"(PS7).

Com a ampliação e a institucionalização dos protocolos restritivos face à pandemia, os documentos aumentaram e as normas se multiplicaram dia a dia. Os participantes reconhecem, no entanto, que a multiplicação de documentos não necessariamente repercute na melhoria dos processos de cuidado. Mencionaram, nessa direção, que os protocolos e normas precisam ser acompanhados de sensibilização e conscientização.

"Mais do que elaborar e seguir normas, ritos e protocolos já bem implantados e definidos internamente é preciso conscientização pessoal e coletiva dos envolvidos no processo"(PS9).

$\mathrm{Na}$ fala de participante ficou evidente a relevância da educação permanente como ferramenta reordenadora do ser e fazer profissional, visto que a mesma se apoia no pressuposto de que a partir do momento em que a equipe multiprofissional compreende o contexto de sua prática, esta poderá provocar reflexões que venham a contribuir com a melhoria da qualidade da assistência. Reconhecem que este processo repercutirá, nos serviços e ao usuário, em continuas e melhores práticas de cuidado e segurança no trabalho. 
“A educação permanente é importante para manter a atualização nos assuntos, interação do grupo, união, curiosidade, capacitação profissional, aperfeiçoamento e isso acaba despertando a vontade de sempre aprender mais e estar numa constante mudança na profissão que nós escolhemos..." (PS13),

Os resultados demostram, em geral, que a pandemia do coronavírus conduziu a um sentimento de retorno às fontes e aos cuidados básicos, tais como a lavagem das mãos e uso correto dos EPIs em ambientes de saúde, embora estudos ainda não evidenciem claramente este processo. Ressalta-se, ainda, que a promoção da segurança do profissional de saúde é fundamental para promover a segurança do paciente.

O processo de educação permanente é de extrema importância no cenário do cuidado, pelo fato de possibilitar paradas necessárias para o repensar sobre o próprio ser e fazer profissionais, promover o diálogo entre os trabalhadores e despertar mudanças na prática assistencial. Nessa direção, estudo denota que o ensino e aprendizagem no ambiente de trabalho promove melhorias na gestão em saúde e, consequentemente, no processo de trabalho (LEMOS, 2016).

As metodologias ativas no processo de educação permanente são essenciais no sentido de possibilitar encontros intersubjetivos e no que se refere às atitudes e posturas profissionais. Sob esse enfoque, a educação permanente em meio a pandemia permitiu o repensar das práticas profissionais cotidianas e, de certa forma, mecanizadas com o propósito de (re)significà-las à luz de novos referências teóricometodológicos de cuidado em saúde (ZINGRA et al., 2020).

A educação permanente considera, primordialmente, demandas do cotidiano das instituições, para as quais se busca o desfecho a partir do conhecimento prévio de cada indivíduo. Nessa relação, as metodologias ativas fomentam a problematização de situações, que induzem à reflexão a partir do vivido dos profissionais inseridos no processo de trabalho (ALMEIDA, 2019).

A educação permanente, sobretudo, em tempos de pandemia se constitui em ferramenta desafiadora e impulsionadora do novo, considerando que a aprendizagem se dá de forma rápida e continua para atingir melhores resultados. O conhecimento passou a ser construído coletivamente pela mediação de tecnologias online e esse 
processo modificou a relação de aprendizagem dos profissionais. A educação permanente, hoje mais do que nunca, valoriza as situações emergentes do trabalho e em seus processos e busca dar respostas rápidas e efetivas face à emergência da pandemia provocada pelo novo coronavírus (BARROSO et al., 2020).

A Educação Permanente em Saúde tem grande importância social na prática transformadora de aprendizagem, visto que os profissionais da área da saúde possam repensar sobre a sua prática de serviço para melhor qualificá-la. Nesse contexto, o Sistema Único de Saúde (SUS), potencializará sua atenção ao cuidado de acordo com as práticas de Educação Permanente em Saúde que forem incorporadas ao sistema de saúde. Desse modo, está prática será agregada através de um dispositivo de autoanálise por parte dos profissionais de saúde. Com isso, as mudanças começam a ocorrer gradativamente visando a melhora do atendimento prestado (CAMPOS; SENA; SILVA., 2017).

\section{CONCLUSÃO}

Os resultados do estudo denotam, que promover a segurança do profissional de saúde, pressupõem desenvolver, a priori, mecanismos de (re)significação e sensibilização voltados à tarefas cotidianas, em meio à pandemia provocada pela Covid-19. Para além de retomar cuidados básicos como, por exemplo, a lavagem de mãos e o uso da máscara, é preciso criar mecanismos de sensibilização para o seu uso correto e permanente.

Conclui-se, em suma, que promover a educação permanente em saúde requer muito mais do que atualizar e (re)significar normas e protocolos de emergência face à pandemia provocada pela Covid-19. Para além disso, é preciso criar espaços acolhedores e estimuladores, nos quais os profissionais de saúde se sintam acolhidos e protegidos, isto é, reconhecidos em suas habilidades e fortalecidos em suas convicções.

\section{AGRADECIMENTOS}

Agradecimento a Fundação de Amparo à Pesquisa do Rio Grande do SulFAPERGS. 


\section{REFERÊNCIAS}

BACKES, D.S. et al. Incubadora de Aprendizagem: ferramenta indutora do empreendedorismo na Enfermagem. Rev. Bras. Enferm., Brasília, v. 68, n.6, p.11031108, 2015. DOI http://dx.doi.org/10.1590/0034-7167.2015680615i

BRASIL. Comissão Nacional de Ética em Pesquisa. Ofício Circular n²/2021. Orientações para procedimentos em pesquisas com qualquer etapa em ambiente virtual.

BRASIL. Conselho Nacional de Saúde. Resolução $n^{\circ}$ 466/2012. Dispõe sobre a realização de pesquisas com seres humanos [Internet].

BRASIL. Ministério da Saúde. Secretaria de Gestão do Trabalho e da Educação na Saúde. Departamento de Gestão da Educação em Saúde. Política Nacional de Educação Permanente em Saúde. Brasília: Ministério da Saúde, 2009.

DANTAS, E.S.O. Saúde mental dos profissionais de saúde no Brasil no contexto da pandemia por Covid-19. Interface (Botucatu), Botucatu, v.25, supl.1, e200203, 2021. DOI: 10.1056 / NEJMp2005492

LISA ROSENBAUM, M.D. Enfrentando COVID-19 na Itália- Ética, logística e terapêutica na linha de frente da epidemia. The New England Jounal of Medicine, v.18, p.1873-1875, 2020.

MINAYO, M.C.S.; COSTA, A.P. Fundamentos Teóricos das Técnicas de Investigação Qualitativa. Revista Lusófona de Educação, v.40, n40, p:139-53, 2018. Disponível em:

https://www.researchgate.net/publication/328403919_Fundamentos_Teoricos_das_ Tecnicas_de_Investigacao_Qualitativa 
ROSSETTI, L.T. et al. Educação permanente e gestão em saúde: a concepção dos enfermeiros. Rev Fun Care Online, v.11, n.1, p.129-134, 2019. DOI http://dx.doi.org/10.9789/2175-5361.2019.v11i1.129-134.

SOUZA, L.P.S; SOUZA, A.G. Enfermagem brasileira na linha de frente contra o novo Coronavírus: quem cuidará de quem cuida? Journal of Nursing and Health, v.10, p.01-13, 2020.

LEMOS, C.L.S. Educação Permanente em Saúde no Brasil: educação ou gerenciamento permanente? Ciência \& Saúde Coletiva, v.21, n.3, p.913-922, 2016. DOI http://dx.doi.org/10.1590/1413-81232015213.08182015.

ZINGRA, K.N. et al. Educação permanente para profissionais da área da saúde como estratégia de combate ao enfrentamento da pandemia de COVID-19 na região norte: relato de experiência. Revista Acervo Saúde, v.12, n. 12, p. 1-7, 2020. DOI https://doi.org/10.25248/reas.e5745.2020.

ALMEIDA, P.P. Metodologias ativas para a cultura de segurança. Revista visa em debate, v.7, n.4, p.96-103, 2019. DOI https://doi.org/10.22239/2317-269x.01349.

BARROSO, B. I. L. et al. A saúde do trabalhador em tempos de COVID-19: reflexões sobre saúde, segurança e terapia ocupacional. Cadernos Brasileiros de Terapia Ocupacional, v.28, n.3, p.1093-1102, 2020. DOI http://dx.doi.org/10.4322/25268910.ctoarf2091

CAMPOS, C., F., K. SENA, R., R. SILVA, L., K. Educação Permanente nos Serviços de Saúde. Esc Anna Nery, v.21, n.4, e20160317, 2017. DOI: 10.1590/2177-9465EAN-2016-0317 